\title{
Donald W. Wiss (ed): Master Techniques in Orthopaedic Surgery-Fractures, 2nd edn
}

\section{3/23/06, 832 pp, 225,00 US\$, Lippincott Williams \& Wilkins, a Wolters Kluver Company Philadelphia, Baltimore, New York, London, Buenos Aires, Hong Kong, Sydney, Tokyo, ISBN 0-7817-5290-6}

\author{
Pierre Kehr • Alain Graftiaux
}

Received: 26 October 2008 / Accepted: 27 October 2008 / Published online: 14 November 2008

(C) Springer-Verlag 2008

It is about a book multi-author particularly well done, treating chapter after chapter of the fractures of the upper limbs then lower, of the basin, but also of the periprothetic fractures as well as covers of losses of substances by scraps (of gastrocnemius and soleus).

Each chapter is treated same manner with initially the indications and against indications, the radiological assessment and preoperative planning, then the surgical technique and the operational care post, and finally the complications.

Each chapter is largely illustrated splendid operational photographs particularly easy to include/understand accompanied if need be by drawings.
The step by step makes it possible each and everyone to follow the described technique well.

On the whole a book particularly well done on the fractures which will be useful as well for the young person in order to be initiated as with the surgeon more trained to find a technique that it does not have the practice to practice in a regular way.

Conflict of interest statement No funds were received in support of this study. 